\title{
'Spring Glow' Cornelian Cherry
}

\section{P.R. Fantz ${ }^{1}$, R.E. Lyons ${ }^{2}$, and J.C. Raulston ${ }^{3}$ \\ Department of Horticultural Science, Box 7609, North Carolina State University, Raleigh, NC 27695-7609}

Additional index words. Cornus, Cornaceae, cornelian cherry, cornelian cherry dogwood, sorbet, ornamentals, breeding

Cornelian cherry (cornelian cherry dogwood, sorbet), Cornus mas L. (Cornaceae), is a deciduous shrub to small tree cultivated as a landscape ornamental for its late winter/early spring flowers, fruits, and foliage. It has been regarded as an excellent plant for northern gardens because it flowers before Forsythia Vahl. and other familar symbols of spring (Tenenbaum, 1994). It is very effective in the landscape as it receives little aesthetic competition from other flowering shrubs (Dirr, 1998). Flowers are yellow, small, clustered on previous year's wood, and bloom for 3 weeks (Dirr, 1998; Lancaster, 1995; Tenenbaum, 1994). Fruits are bright cherry-red, ripening in the summer, and effective for attracting birds (Lancaster, 1995; Tenenbaum, 1994). The fruits are used for syrups and preserves (Dirr, 1998; Tenenbaum, 1994). Leaves typically are dark green and somewhat glossy (Dirr, 1998) with a yellow to red fall foliage color (Tenenbaum, 1994), although the leaves may abscise in late fall while still green (Dirr, 1998). Cornus mas is utilized as a hedge, screen, shrub border, or foundation plant in landscape designs (Dirr, 1998) and is regarded as pest free (Dirr, 1998; Tenenbaum, 1994). This species is one of the toughest, most drought-tolerant trees for cities in the Northeast and Midwest (Tenenbaum, 1994) and most durable of the dogwoods (Dirr, 1998).

Several cultivars have been selected, usually for the color or size of the fruits or leaves (Dirr, 1998). Cornus mas 'Spring Glow' is precocious and floriferous. It is unique in presenting flowers that are larger in size and appear 1 to 2 weeks earlier than other representatives of the species. The objective of this article is to document the data on Cornus mas 'Spring Glow', selected as a release of new germplasm from the JC Raulston Arboretum.

\section{Origin}

Raulston discovered a seedling of Cornus mas in 1990 that bloomed earlier than other seedlings. It exhibited larger, showier flowers and glossy foliage with a thick leathery

Received for publication 6 June 2001. Accepted for publication 8 Oct. 2001. The use of nursery and trade names in this publication does not imply endorsement by the North Carolina Agricultural Research Service of the nursery or the products mentioned, nor criticism of similar ones not mentioned.

${ }^{1}$ Professor

${ }^{2} \mathrm{JC}$ Raulston Distinguished Professor and Director of JC Raulston Arboretum, North Carolina State Univ. ${ }^{3}$ Deceased. Former Professor and Director of the North Carolina State Univ. Arboretum. texture. Mass propagation of 'Spring Glow' was accomplished during 1991 in the nursery of the North Carolina State Univ. (NCSU) Arboretum (currently renamed as the JC Raulston Arboretum). 'Spring Glow' was distributed to arboretum contributors as one of the "connoisseur" plants (Raulston, 1993). Raulston had chosen 'Spring Glow' as the official name of this new cultivar selection, emphasizing its early blooming performance. He distributed some germplasm to associates for evaluation, but met an untimely death before the germplasm could be officially released.

\section{Description}

'Spring Glow' is a deciduous shrub (Fig. 1). Leaves are opposite, elliptic, short acuminate, $7.5-11 \mathrm{~cm}$ long, and $4.5-7 \mathrm{~cm}$ wide. Petioles are 7-11 mm long. There are 1-3 subsessile inflorescences that are borne terminally on opposite, short $(0.5-1 \mathrm{~cm})$, lateral branches borne from the axils of older wood before the leaf buds open. Peduncles are 2-4 mmlong and densely grayish-tomentose. There are 2-4 pairs of clasping navicular bracts that are oblong-ovate, weakly keeled, acute, and mucronate, with pubescence similar to the peduncle. There are two pairs of decussate involucral bracts 5-6 $\mathrm{mm}$ long, 4-6 $\mathrm{mm}$ wide, concave-oval, keeled, obtuse, mucronate, and with similar pubescence as the bracts. These bracts are erect, hiding the floral buds and spreading slightly as flowers mature. Flowers are numerous (20-25) and are borne in a subsessile umbel that barely exceeds the spreading involucre. Pedicels are slender, densely strigose-tomentose, $2-5 \mathrm{~mm}$ long, and lengthen to $8 \mathrm{~mm}$ with matured flowers. The calyx tube is $1 \mathrm{~mm}$ long, densely strigosetomentose, with four glabrate, deltoidcymbiform lobes $\approx 0.4 \mathrm{~mm}$ long. The disk is yellowish and $\approx 0.7-0.8 \mathrm{~mm}$ in diameter. The four petals are bright yellow, spreading, becoming strongly reflexed with age, deltoid with a rapid taper to an acute apex, and 2-2.5 $\mathrm{mm}$ long $\times 1 \mathrm{~mm}$ wide basally. The four stamens alternate with the petals and bear dorsifix anthers on 1-mm-long filaments. The ovary is inferior with a style $\approx 1.2 \mathrm{~mm}$ long. HolotyPe: Fantz 6209 (NCSC); PARATYPE: Fantz 6628 (NCSC)

Observations. The holotypic standard (or cultivar type) for 'Spring Glow' is planted in Kilgore Mounds at NCSU. The plant blooms in late February to early March in the Raleigh area, and was $\approx 6$ feet tall at age 7 years. 'Spring

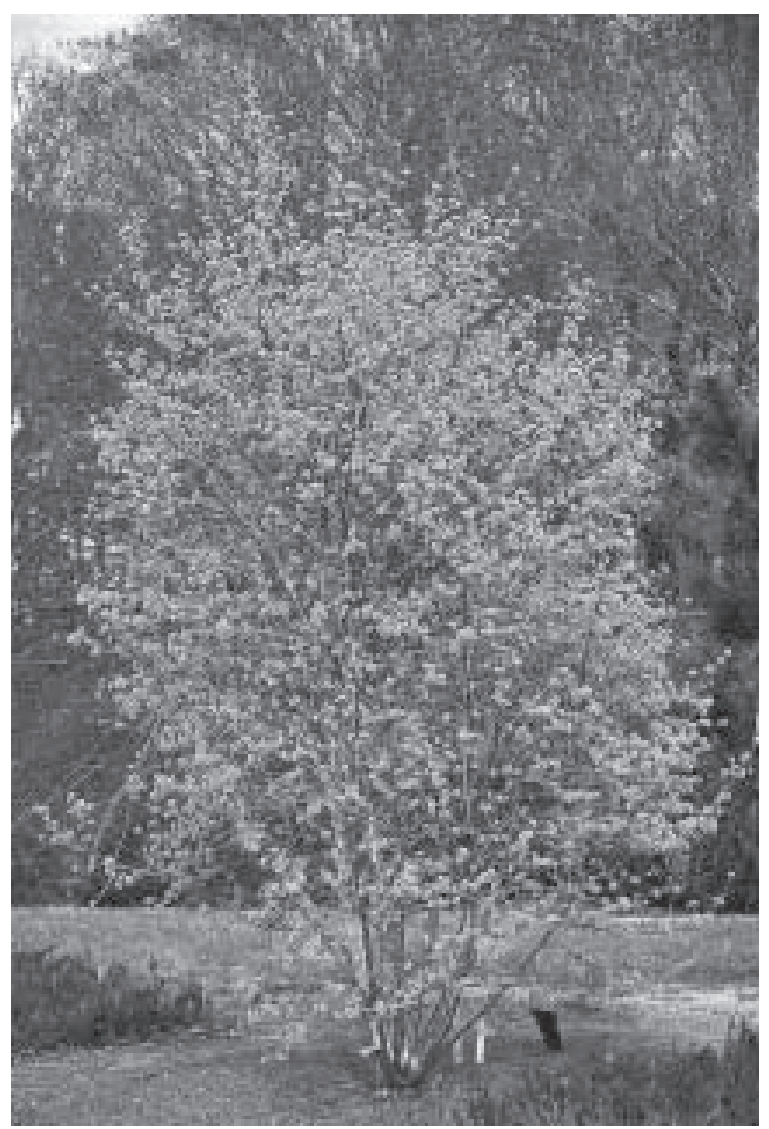

Fig. 1. Habit of 'Spring Glow' in flower. Photograph by J.C. Raulston (slide \#113-696). 
Glow' is unique in bearing glossy foliage with a thick leathery texture that remains ornamentally attractive until frost (Raulston, 1993; Russell and Buendia, 1996) and is regarded as the most heat-tolerant and free-flowering selection of Cornus mas.

\section{Culture}

'Spring Glow' is propagated by softwood to semi-hardwood cuttings under mist in summer (Russell and Buendia, 1996), performs best in USDA Zones 4-8, and tolerates difficult soil conditions (Raulston, 1993). It grows in full sun (Raulston, 1993) to partial shade (Gilman and Watson, 1993), and is used as a specimen plant, in hedges, container, or above- ground planters, or near a deck or patio (Gilman and Watson, 1993).

\section{Availability}

Information on availability of 'Spring Glow' can be obtained from the JC Raulston Arboretum, Dept. of Horticultural Science, Box 7609, North Carolina State Univ., Raleigh, NC 27695-7609.

\section{Literature Cited}

Dirr, M.A. 1998. Manual of woody landscape plants: Their identification, ornamental characteristics, culture, propagation and uses. 5th ed. p. 268-269. Stipes Publ. Co., Champaign, Ill.
Gilman, E.F. and D.G. Watson. 1993. Cornus mas 'Spring Glow', 'Spring Glow' Cornelian Cherry. U.S. Dept. Agr., Forest Service Fact Sheet ST-197. (http://hort.ifas.ufl.edu/Trees/ ComList.HTM\#C). [Sept. 2000].

Lancaster, R. 1995. What plant where. Dorling Kindersley, London.

Raulston, J.C. 1993. 1993 Connoisseur plants for NCSU Arboretum sustaining and corporate contributors. (http://www.ncsu.edu/jcraulston arboretum/). [Sept. 2000].

Russell, A.B. and M.A. Buendia. 1996. Ornamental plant cultivars selected, named and introduced by the NCSU Arboretum (now the JC Raulston Arboretum). (http://www.ncsu.edu/ jcraulstonarboretum/). [Sept. 2000].

Tenenbaum, F. (ed.). 1994. Taylor's master guide to gardening. Houghton Mifflin, Boston. 